\title{
Evaluating the efficacy of post-surgery adjuvant therapies used for ductal carcinoma in situ patients: a network meta-analysis
}

\author{
Li Wang ${ }^{1,4, *}$, Yaoxiong Xiaa, ${ }^{1,4}{ }^{*}$, Dequan Liu' ${ }^{2,4, *}$, Yueqin Zeng ${ }^{3}$, Li Chang ${ }^{1,4}$, Lan $\mathbf{L i}^{1,4}$, \\ Yu Hou ${ }^{1,4}$, Lv Ge ${ }^{4}$, Wenhui $\mathrm{Li}^{1,4}$ and Zhijie Liu ${ }^{3}$ \\ ${ }^{1}$ Department of Radiation Oncology, The Third Affiliated Hospital of Kunming Medical University, Tumor Hospital of Yunnan \\ Province, Kunming, Yunnan, China \\ 2 Department of Breast surgery, the Third Affiliated Hospital of Kunming Medical University, Tumor Hospital of Yunnan \\ Province, Kunming, Yunnan, China \\ ${ }^{3}$ Department of Breast Surgery, The Third Affiliated Hospital of Kunming Medical University, Tumor Hospital of Yunnan \\ Province, Kunming, Yunnan, China \\ ${ }^{4}$ The Third Affiliated Hospital of Kunming Medical University, Tumor Hospital of Yunnan Province, Kunming, Yunnan, China \\ * These authors are first authors
}

Correspondence to: Zhijie Liv, email: zhijieliv15@126.com

Wenhui Li, email: z_yhs163@163.com

Keywords: ductal carcinoma in situ, radiotherapy, tamoxifen, anastrozole, network-meta-analysis

Received: October 21, $2016 \quad$ Accepted: March 16, $2017 \quad$ Published: April 21, 2017

Copyright: Wang et al. This is an open-access article distributed under the terms of the Creative Commons Attribution License 3.0 (CC BY 3.0), which permits unrestricted use, distribution, and reproduction in any medium, provided the original author and source are credited.

\section{ABSTRACT}

Objective: Post-surgery adjuvant therapies are very important for patients suffering from ductal carcinoma in situ (DCIS). In this study we conducted a network meta-analysis (NMA) to evaluate the efficacy of different post-surgery adjuvant therapies including tamoxifen, anastrozole and radiation therapy (RT) and their combinations (RT+ tamoxifen and RT+ anastrozole).

Methods: We searched several databases, including Embase, MEDLINE / PUBMED, Cochrane Library, and Science Citation Index, for relevant studies. We then extracted the data from eligible studies in order to perform our NMA. We measured the comparative efficacy of each treatment option based on the calculated odds ratios (ORs) and the corresponding $95 \%$ credibility interval (95\% CrI) for each treatment option. We calculated the surfaces under the cumulative ranking curves (SUCRA) in order to rank the therapies according to their different outcomes.

Results: In this study, local recurrence (LC) was chosen as the primary outcome. Metastasis, contralateral-breast cancer (CBC), ipsilateral-breast cancer (IBC) and death were secondary outcomes. Patients treated with RT and RT + tamoxifen exhibited a lower risk of LC compared with control group (OR=0.54, 95\%CrI: 0.400.73; OR=0.41, 95\%CrI: 0.19-0.90). Patients treated by RT and RT + tamoxifen also exhibited a significantly lower risk of IBC compared with control group (OR $=0.55$, 95\%CrI: 0.37-0.82; OR=0.42, 95\%CrI: 0.18-0.99). Results from the SUCRA indicated that RT + anastrozole and RT + tamoxifen were potentially the best adjuvant treatments for patients with DCIS.

Conclusions: In conclusion, the RT + anastrozole and RT + tamoxifen are recommended for their performance and effectiveness.

\section{INTRODUCTION}

Ductal carcinoma in situ (DCIS) of the breast is the result of the clonal proliferation of malignant-appearing cells contained in the mammary duct lumens. It is a precursor to invasive breast carcinoma [1]. It is estimated that $45-78 \%$ of invasive breast carcinomas are associated with DCIS [2]. Although DCIS itself has a relatively low risk of metastasis [3], about $25 \%$ to $50 \%$ of DCIS patients eventually develop invasive cancers [4]. In cases of invasive relapse, the patient survival rate is about $15 \%$ 
[5]. The discovery of similar chromosomal changes in DCIS and invasive cancers patients suggests a potential relationship between DCIS and invasive cancers $[6,7]$.

Although DCIS is usually not detectable in its early stages, mammographic screening techniques can be used to detect it before clinical symptoms are generally observable $[3,8]$. The number of diagnosed DCIS cases in the US has increased notably after mammographic screening techniques were introduced [9].

Traditional mastectomy is frequently used to prevent local recurrence (LC) in patients with DCIS, however it may cause severe side effects $[3,10,11]$. As a result, the conventional mastectomy has been replaced by breast-conserving surgery (BCS) with or without the use of adjuvant endocrine or radiation therapy (RT) [12]. Randomized controlled trials (RCTs) in previous studies have indicated a remarkable decrease in the risk of LC among DCIS patients who were managed by postlumpectomy RT [13, 14]. Another (National Surgical Adjutant Breast/Bowel Project) NSABP B-17 trial suggested that the LC rate during an eight-year period decreased to $12 \%$ in DCIS patients with postoperative RT [13]. Some consistent results were reported The European Cooperative Study Group Trial (EORTC), reported consistent results in their study of 1,010 females who were diagnosed with DCIS [14]. These trials demonstrated that RT could reduce the risk of LC in DCIS patients.

On the other hand, tamoxifen is often used as an adjuvant endocrine therapy for invasive breast carcinoma and it is able to reduce the risk of LC and death [4]. Moreover, tamoxifen has gradually gained use as an adjuvant therapy for DCIS patients in order to prevent ipsilateral and contralateral failure. In the NSABP B-24 trial, females with tamoxifen therapy following BCS and post-lumpectomy irradiation had significantly fewer breast cancer events than those with placebo during an 83-month follow-up period [15]. The effectiveness of tamoxifen in patients treated by BCS and postoperative RT has been verified and hence tamoxifen is often recommended to DCIS patients in order to prevent invasion [4].

Anastrozole is a non-steroidal aromatase-inhibiting medication. It is also an approved treatment option for breast cancer patients and it has been suggested that it is even more effective than tamoxifen with respect to disease progression and overall response rates [16]. Although anastrozole and tamoxifen have similar side effects and toxicity, patients treated by anastrozole exhibited fewer thromboembolic events compared to those treated by tamoxifen [15]. The ATAC6 trial, which was conducted in females with early-stage invasive breast carcinoma, revealed similar results [17]. In addition, patients treated with anastrozole were associated with fewer cases of deepvein thrombosis, hot flush, endometrial cancer and stroke compared with those treated by tamoxifen [15].

However, there is no NMA comparing different adjuvant therapies for patients with DCIS. This NMA was conducted to compare the efficacy of various postoperative adjuvant therapies for patients suffering from DCIS in order to evaluate the performance of different post-surgery treatments and provide grounded information for clinical practice. The therapies considered include: tamoxifen, anastrozole, RT, RT + tamoxifen and RT + anastrozole. The control group, set up for the purpose of comparison, consisted of patients treated with placebo. This study used endpoints, including LC, metastasis (M), contralateral breast cancer (CBC), ipsilateral-breast cancer (IBC) and death (D) to assess the efficacy of the above treatments.

\section{RESULTS}

\section{Literature selection}

As shown in Figure 1, study selection was carried out in three steps: study identification, screening and inclusion. We identified a total of 2,369 studies, 2,346 of which were identified using the literature search strategy outlines above, and 23 of which were identified by additional reviews. However, only 84 full-length articles were retrieved and the remaining articles were rejected due to duplication, insufficient information or irrelevant outcomes. Another 36 articles were excluded because of insufficient data, insufficient network connections or irrelevant outcomes. Therefore, 48 eligible publications were eventually subject to data extraction $[13,15,18$ 63]. The detailed characteristics of eligible studies are displayed in Table 1. Of the 48 eligible studies, 29 were observational studies and the other 19 were RCTs. A total of 41,922 patients were included in our NMA and the corresponding following-up duration of each study ranged from 3 to 20 years. Up to 40 studies covered the comparison of the RT group and control group. The network plot for each outcome is illustrated in Figure 2, in which each node corresponds to a post-surgery adjuvant therapy and each solid line corresponds to a direct comparison between two therapies. The thickness of solid lines is proportional to the number of direct comparisons between two therapies whereas the size of nodes is proportional to the sample size involved in each therapy.

\section{Analysis based on both observational studies and RCTs}

All eligible studies, including observational studies and RCTs, were included in the analysis procedure. The results are shown in the lower diagonal of Table 2 and in Figure 3. Patients treated by RT, and RT + tamoxifen were associated with a significantly decreased risk of LC compared to the control group (RT: $\mathrm{OR}=0.54,95 \% \mathrm{CrI}=$ 0.40-0.73; RT + Tamoxifen: $\mathrm{OR}=0.41,95 \% \mathrm{CrI}=0.19$ $0.90)$. Similarly, RT and RT + tamoxifen were associated 
with a lower risk of IBC compared to the control group $(\mathrm{OR}=0.55,95 \% \mathrm{CrI}=0.37-0.82 ; \mathrm{OR}=0.42,95 \% \mathrm{CrI}$ $=0.18-0.99$, respectively). No statistically significance differences were observed with regard to the outcomes $\mathrm{CBC}, \mathrm{D}$ and $\mathrm{M}$.

\section{Analysis based on RCTs}

In order to ensure that included observational studies did not introduce bias into this NMA, RCTs were selected from eligible studies and then analyzed using the same method. The corresponding results of our NMA are displayed in the upper diagonal of Table 2 and Figure 4. The results of the RCTs were similar to those of the observational studies, which indicated that the inclusion of observational studies introduced little heterogeneity to this NMA. Patients treated with RT and $\mathrm{RT}+$ tamoxifen exhibited a lower risk of LC compared to the control group $(\mathrm{OR}=0.53,95 \% \mathrm{CrI}=0.32-0.92$; OR $=0.31,95 \% \mathrm{CrI}=0.12-0.79$, respectively). Moreover, patients with RT+ tamoxifen also exhibited a lower risk of $\mathrm{LC}$ compared with tamoxifen alone $(\mathrm{OR}=0.28,95 \%$ $\mathrm{CrI}=0.10-0.68)$. Additionally, RT was associated with a lower risk of IBC compared to the control group (OR = $0.47,95 \% \mathrm{CrI}=0.27-0.84$ ) and there was no statistically significant difference among different treatments in terms of $\mathrm{M}$ and D. However, RT was associated with a higher risk of $\mathrm{CBC}$ compared with the control group $(\mathrm{OR}=1.48$,

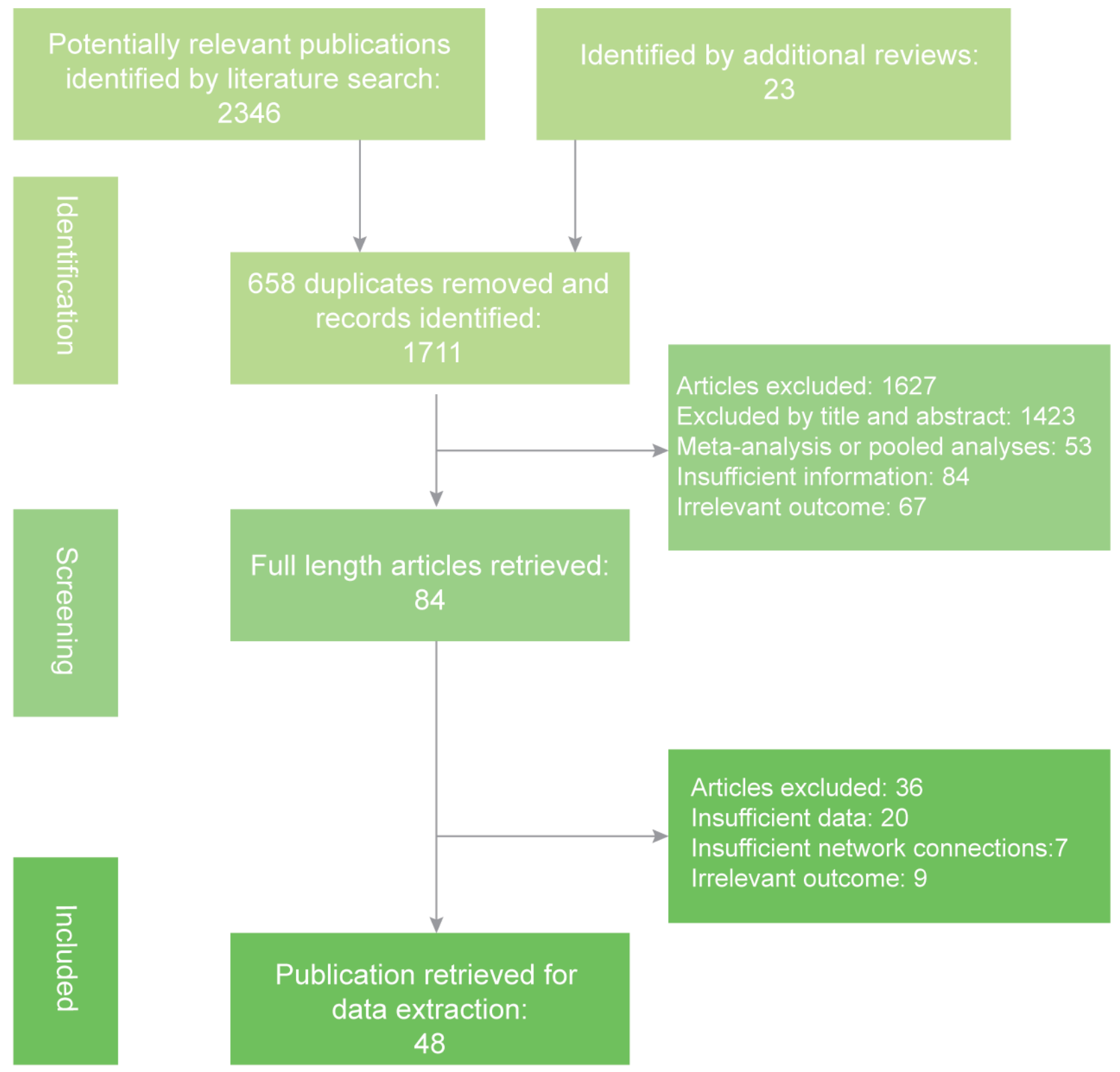

Figure 1: Flow chart of literature search, screening and inclusion. 
Table 1: Baseline characteristics of included studies

\begin{tabular}{|c|c|c|c|c|c|c|c|c|c|c|c|c|c|c|}
\hline \multirow{2}{*}{ Study } & \multirow{2}{*}{ Country } & \multirow{2}{*}{ Design } & \multirow{2}{*}{ Subgroup by } & \multirow{2}{*}{$\begin{array}{l}\text { Follow-up } \\
\text { (months) }\end{array}$} & \multirow{2}{*}{ Surgery } & \multicolumn{2}{|c|}{ Group 1} & \multicolumn{2}{|c|}{ Group 2} & \multicolumn{5}{|c|}{ Outcomes } \\
\hline & & & & & & Size & Therapy & Size & Therapy & $\mathrm{LC}$ & M & $\mathrm{CBC}$ & IBC & D \\
\hline Baird, 1990 & Multicenter & $\mathrm{nRCT}$ & - & 30 & Mastectomy & 30 & Control & 8 & RT & $\sqrt{ }$ & & & & \\
\hline Ben-David, 2007 & USA & $\mathrm{RCT}$ & - & 48 & $\mathrm{BCS}$ & 48 & $\mathrm{RT}+$ Tamoxifen & 150 & RT & $\sqrt{ }$ & & & $\sqrt{ }$ & \\
\hline Bijker, 2006 & Multicountry & $\mathrm{RCT}$ & - & 503 & LE & 503 & RT & 507 & Control & $\sqrt{ }$ & $\sqrt{ }$ & $\sqrt{ }$ & & $\sqrt{ }$ \\
\hline Bijker, 2001 & European & $\mathrm{nRCT}$ & - & 134 & LE & 134 & Control & 159 & RT & & $\sqrt{ }$ & & & $\sqrt{ }$ \\
\hline Boyages, 1999 & Australia & $\mathrm{nRCT}$ & - & 289 & $\mathrm{BCS}$ & 289 & Control & 357 & RT & $\sqrt{ }$ & & & & \\
\hline Cataliotti, 1992 & Italy & $\mathrm{nRCT}$ & margin status & 123 & $\mathrm{BCS}$ & 123 & RT & 167 & Control & $\sqrt{ }$ & & & & \\
\hline \multirow[t]{2}{*}{ Chan, 2001} & Multicenter & nRCT & margin status & 129 & $\mathrm{BCS}$ & 129 & Control & 18 & RT & $\sqrt{ }$ & & & & \\
\hline & & & & 27 & $\mathrm{BCS}$ & 27 & Tamoxifen & 9 & $\mathrm{RT}+$ Tamoxifen & $\sqrt{ }$ & & & & \\
\hline Chuwa, 2008 & Multicenter & nRCT & margin status & 67 & $\mathrm{BCS}$ & 67 & Tamoxifen & 103 & RT+Tamoxifen & $\sqrt{ }$ & & $\sqrt{ }$ & & \\
\hline Cutuli, 2002 & France & nRCT & age & 515 & $\mathrm{BCS}$ & 515 & RT & 190 & Control & $\sqrt{ }$ & $\sqrt{ }$ & & & \\
\hline Cutuli, 2001 & Multicenter & nRCT & age & 136 & $\mathrm{BCS}$ & 136 & Control & 435 & RT & $\sqrt{ }$ & & & & \\
\hline \multirow[t]{2}{*}{ Cuzick, 2011} & Multicenter & $\mathrm{RCT}$ & grade, age & 567 & WLE & 567 & Tamoxifen & 316 & $\mathrm{RT}+$ Tamoxifen & $\sqrt{ }$ & & & & \\
\hline & & & & 544 & WLE & 544 & Control & 267 & RT & $\sqrt{ }$ & & & & \\
\hline Di Saverio, 2008 & USA & $\mathrm{nRCT}$ & age, size of lesion, VNPI & 186 & $\mathrm{BCS}$ & 186 & Control & 73 & RT & $\sqrt{ }$ & & & & $\sqrt{ }$ \\
\hline Donker, 2013 & European & $\mathrm{RCT}$ & - & 503 & $\mathrm{LE}$ & 503 & Control & 507 & RT & $\sqrt{ }$ & $\sqrt{ }$ & & & $\sqrt{ }$ \\
\hline Emdin, 2006 & Sweden & $\mathrm{RCT}$ & - & 526 & BSR & 526 & RT & 520 & Control & $\sqrt{ }$ & $\sqrt{ }$ & $\sqrt{ }$ & $\sqrt{ }$ & $\sqrt{ }$ \\
\hline Fentiman, 1998 & Multicenter & $\mathrm{nRCT}$ & - & 405 & WLE & 405 & Control & 413 & RT & & & & $\sqrt{ }$ & \\
\hline Fisher, 2007 & Multicountry & $\mathrm{nRCT}$ & - & 734 & LE & 734 & RT & 722 & RT+Tamoxifen & $\sqrt{ }$ & $\sqrt{ }$ & $\sqrt{ }$ & & \\
\hline \multirow[t]{2}{*}{ Fisher, 2001} & - & RCT & - & 403 & Lumpectomy & 403 & Control & 410 & RT & & $\sqrt{ }$ & $\sqrt{ }$ & $\sqrt{ }$ & $\sqrt{ }$ \\
\hline & & & & 899 & Lumpectomy & 899 & RT & 899 & RT+Tamoxifen & & $\sqrt{ }$ & $\sqrt{ }$ & $\sqrt{ }$ & $\sqrt{ }$ \\
\hline Fisher, 2001 & NSAPB & $\mathrm{RCT}$ & - & 522 & Lumpectomy & 522 & Control & 517 & RT & & & & & $\sqrt{ }$ \\
\hline Fisher, 1999 & Multicenter & $\mathrm{RCT}$ & margin status & 899 & Lumpectomy & 899 & RT & 899 & RT+Tamoxifen & & $\sqrt{ }$ & $\sqrt{ }$ & $\sqrt{ }$ & $\sqrt{ }$ \\
\hline Fisher, 1999 & USA & RCT & - & 303 & Lumpectomy & 303 & Control & 320 & RT & & & & $\sqrt{ }$ & \\
\hline Fisher, 1995 & Multicenter & $\mathrm{RCT}$ & margin status & 274 & Lumpectomy & 274 & Control & 299 & RT & & & & $\sqrt{ }$ & \\
\hline Fisher, 1993 & UK & $\mathrm{RCT}$ & - & 391 & Lumpectomy & 391 & Control & 399 & RT & & $\sqrt{ }$ & $\sqrt{ }$ & $\sqrt{ }$ & $\sqrt{ }$ \\
\hline Forbes, 2016 & Multicenter & RCT & invasive breast cancer & 1489 & LE & 1489 & Tamoxifen & 1449 & Anastrozole & $\sqrt{ }$ & & & & $\sqrt{ }$ \\
\hline Habel, 1998 & Multicenter & $\mathrm{nRCT}$ & - & 248 & $\mathrm{BCS}$ & 248 & Control & 293 & RT & $\sqrt{ }$ & & & & \\
\hline Holmberg, 2008 & Sweden & $\mathrm{RCT}$ & age, size of lesion & 526 & $\mathrm{BCS}$ & 526 & RT & 520 & Control & & $\sqrt{ }$ & $\sqrt{ }$ & $\sqrt{ }$ & $\sqrt{ }$ \\
\hline \multirow[t]{2}{*}{ Houghton, 2003} & Multicenter & $\mathrm{RCT}$ & age & 544 & LE & 544 & Control & 567 & Tamoxifen & $\sqrt{ }$ & & & $\sqrt{ }$ & \\
\hline & & & & 267 & LE & 267 & RT & 316 & RT+Tamoxifen & $\sqrt{ }$ & & & $\sqrt{ }$ & \\
\hline Jha, 2001 & UK & nRCT & - & 94 & WLE & 94 & RT & 30 & Control & $\sqrt{ }$ & & & & \\
\hline Julien, 2000 & Multicountry & RCT & - & 503 & LE & 503 & Control & 507 & RT & $\sqrt{ }$ & $\sqrt{ }$ & $\sqrt{ }$ & & $\sqrt{ }$ \\
\hline Kestin, 2000 & USA & $\mathrm{nRCT}$ & - & 36 & Lumpectomy & 36 & RT & 142 & Control & & $\sqrt{ }$ & $\sqrt{ }$ & $\sqrt{ }$ & \\
\hline Kuske, 1993 & USA & $\mathrm{nRCT}$ & - & 70 & Lumpectomy & 70 & RT & 7 & Control & $\sqrt{ }$ & & & & \\
\hline Lagios, 1989 & USA & $\mathrm{nRCT}$ & - & 230 & Lumpectomy & 230 & RT & 101 & Control & $\sqrt{ }$ & & & & \\
\hline Lara, 2003 & USA & $\mathrm{nRCT}$ & - & 86 & Mastectomy & 86 & RT & 16 & Control & & & $\sqrt{ }$ & & \\
\hline Margolese, 2016 & USA/Canada & $\mathrm{RCT}$ & - & 1538 & Lumpectomy & 1538 & $\mathrm{RT}+\mathrm{Tamoxifen}$ & 1539 & $\mathrm{RT}+$ Anastrozole & $\sqrt{ }$ & $\sqrt{ }$ & $\sqrt{ }$ & $\sqrt{ }$ & \\
\hline McCormick, 2015 & Multicenter & RCT & - & 298 & $\mathrm{BCS}$ & 298 & Tamoxifen & 287 & RT+Tamoxifen & $\sqrt{ }$ & & $\sqrt{ }$ & & \\
\hline Meijnen, 2008 & - & nRCT & - & 91 & WLE & 91 & Control & 119 & RT & $\sqrt{ }$ & $\sqrt{ }$ & $\sqrt{ }$ & & $\sqrt{ }$ \\
\hline Miller, 2001 & Multicenter & $\mathrm{nRCT}$ & - & 88 & Lumpectomy & 88 & Control & 18 & RT & $\sqrt{ }$ & & & $\sqrt{ }$ & \\
\hline Omlin, 2006 & Multicountry & nRCT & - & 166 & $\mathrm{BCS}$ & 166 & RT & 57 & Control & $\sqrt{ }$ & & & & \\
\hline Rakovitch, 2007 & USA & $\mathrm{nRCT}$ & age & 310 & $\mathrm{BCS}$ & 310 & Control & 305 & RT & $\sqrt{ }$ & & & & \\
\hline Ringberg, 2000 & Multicenter & $\mathrm{nRCT}$ & grade & 66 & $\mathrm{BCS}$ & 66 & RT & 121 & Control & $\sqrt{ }$ & & & & \\
\hline Rudlof, 2010 & USA & $\mathrm{nRCT}$ & age, number of excision & 935 & BCS & 935 & Control & 906 & RT & & & & $\sqrt{ }$ & \\
\hline Schouten Vn Der, 2007 & Netherland & $\mathrm{nRCT}$ & - & 237 & $\mathrm{BCS}$ & 237 & Control & 153 & RT & $\sqrt{ }$ & & & & \\
\hline Silverstein, 2000 & USA & $\mathrm{nRCT}$ & VNPI, margin status & 209 & $\mathrm{BCS}$ & 209 & RT & 252 & Control & $\sqrt{ }$ & $\sqrt{ }$ & & & $\sqrt{ }$ \\
\hline Smith, 2006 & Multicenter & $\mathrm{nRCT}$ & risk of cancer, age & 1676 & $\mathrm{BCS}$ & 1676 & RT & 1733 & Control & $\sqrt{ }$ & & & $\sqrt{ }$ & \\
\hline Tunon-de-Lara, 2010 & France & $\mathrm{nRCT}$ & - & 67 & Lumpectomy & 67 & Control & 66 & RT & $\sqrt{ }$ & $\sqrt{ }$ & & & \\
\hline \multirow[t]{2}{*}{ Wapnir, 2011} & Multicenter & RCT & age & 900 & Lumpectomy & 900 & RT & 899 & RT+Tamoxifen & $\sqrt{ }$ & $\sqrt{ }$ & & & $\sqrt{ }$ \\
\hline & & & & 403 & Lumpectomy & 403 & Control & 410 & RT & $\sqrt{ }$ & & & & $\sqrt{ }$ \\
\hline Wärnberg, 2014 & Sweden & $\mathrm{RCT}$ & - & 526 & BCS & 526 & RT & 520 & Control & & $\sqrt{ }$ & $\sqrt{ }$ & $\checkmark$ & $\sqrt{ }$ \\
\hline Warren, 2005 & Multicenter & nRCT & tumor size & 626 & BCS & 626 & RT & 477 & Control & & & & $\sqrt{ }$ & $\sqrt{ }$ \\
\hline Weng, 2000 & USA & nRCT & - & 24 & LS & 24 & Control & 38 & RT & $\sqrt{ }$ & & & & \\
\hline
\end{tabular}

Abbreviations: VNPI, Van Nuys Prognostic Index; BSC, breast-conserving surgery; LE, local excision; WLE, wide local excision; BSR, breast sector resection; LS, localized surgery; LC, local recurrence; M, metastasis; D, death; IBC, ipsilateralbreast cancer; $\mathrm{CBC}$, contralateral breast cancer; RT, radiation therapy; RCT, randomized controlled trials; nRCT, nonrandomized controlled trials 
Table 2: Results of network comparison

\begin{tabular}{|c|c|c|c|c|c|c|c|}
\hline \multicolumn{8}{|c|}{$\mathbf{L C}$} \\
\hline \multirow{6}{*}{ nRCT+RCT } & Control & $0.99(0.19,6.23)$ & $0.53(0.32,0.92)$ & $0.22(0.04,1.22)$ & $0.31(0.12,0.79)$ & $1.12(0.43,3.46)$ & \multirow{6}{*}{ RCT } \\
\hline & $0.72(0.13,4.06)$ & Anastrozole & $0.53(0.09,2.92)$ & $0.23(0.02,1.92)$ & $0.31(0.05,1.62)$ & $1.13(0.28,4.62)$ & \\
\hline & $0.54(0.40,0.73)$ & $0.76(0.14,4.26)$ & RT & $0.42(0.08,2.14)$ & $0.59(0.25,1.32)$ & $2.10(0.78,6.42)$ & \\
\hline & $0.30(0.06,1.54)$ & $0.41(0.05,3.78)$ & $0.55(0.11,2.77)$ & RT+Anastrozole & $1.39(0.35,5.58)$ & $4.95(0.97,29.37)$ & \\
\hline & $0.41(0.19,0.90)$ & $0.57(0.11,3.06)$ & $0.76(0.36,1.62)$ & $1.39(0.33,5.81)$ & RT+Tamoxifen & $3.60(1.46,10.07)$ & \\
\hline & $0.81(0.31,2.08)$ & $1.13(0.27,4.81)$ & $1.49(0.57,3.78)$ & $2.75(0.51,14.15)$ & $1.97(0.84,4.44)$ & Tamoxifen & \\
\hline \multicolumn{8}{|c|}{ CBC } \\
\hline \multirow{5}{*}{ nRCT+RCT } & Control & $1.48(1.14,1.92)$ & $0.48(0.22,1.06)$ & $0.76(0.44,1.31)$ & $0.72(0.25,2.14)$ & \multirow{5}{*}{ RCT } & \\
\hline & $0.95(0.44,1.82)$ & RT & $0.33(0.15,0.69)$ & $0.52(0.32,0.83)$ & $0.49(0.17,1.43)$ & & \\
\hline & $0.38(0.03,4.85)$ & $0.39(0.03,4.95)$ & RT+Anastrozole & $1.57(0.89,2.80)$ & $1.48(0.50,4.57)$ & & \\
\hline & $0.58(0.12,2.44)$ & $0.61(0.17,2.27)$ & $1.55(0.18,13.60)$ & RT+Tamoxifen & $0.94(0.38,2.46)$ & & \\
\hline & $0.41(0.04,3.67)$ & $0.43(0.05,3.67)$ & $1.12(0.07,16.78)$ & $0.71(0.12,3.82)$ & Tamoxifen & & \\
\hline \multicolumn{8}{|c|}{ IBC } \\
\hline \multirow{5}{*}{ nRCT+RCT } & Control & $0.47(0.27,0.84)$ & $0.30(0.05,2.03)$ & $0.36(0.13,1.01)$ & $0.84(0.17,4.10)$ & \multirow{5}{*}{ RCT } & \\
\hline & $0.55(0.37,0.82)$ & RT & $0.64(0.11,3.97)$ & $0.77(0.34,1.77)$ & $1.77(0.33,9.49)$ & & \\
\hline & $0.35(0.07,1.84)$ & $0.64(0.13,3.16)$ & RT+Anastrozole & $1.20(0.24,5.93)$ & $2.77(0.23,32.79)$ & & \\
\hline & $0.42(0.18,0.99)$ & $0.77(0.36,1.63)$ & $1.20(0.29,4.95)$ & RT+Tamoxifen & $2.32(0.35,15.03)$ & & \\
\hline & $0.83(0.20,3.35)$ & $1.52(0.35,6.42)$ & $2.36(0.27,20.09)$ & $1.97(0.38,9.87)$ & Tamoxifen & & \\
\hline \multicolumn{8}{|c|}{$\mathbf{M}$} \\
\hline \multirow{4}{*}{ nRCT+RCT } & Control & $1.14(0.84,1.57)$ & $0.45(0.10,1.80)$ & $0.84(0.44,1.38)$ & \multirow{4}{*}{ RCT } & & \\
\hline & $1.13(0.86,1.49)$ & RT & $0.40(0.09,1.52)$ & $0.73(0.42,1.07)$ & & & \\
\hline & $0.43(0.09,1.75)$ & $0.38(0.09,1.48)$ & RT+Anastrozole & $1.82(0.50,7.24)$ & & & \\
\hline & $0.80(0.45,1.25)$ & $0.71(0.42,1.01)$ & $1.84(0.50,7.39)$ & RT+Tamoxifen & & & \\
\hline \multicolumn{8}{|c|}{ D } \\
\hline \multirow{3}{*}{ nRCT+RCT } & Control & $1.02(0.79,1.32)$ & $0.98(0.57,1.68)$ & \multirow{3}{*}{ RCT } & & & \\
\hline & $0.99(0.73,1.32)$ & RT & $0.97(0.59,1.55)$ & & & & \\
\hline & $0.95(0.47,1.90)$ & $0.96(0.52,1.79)$ & RT+Tamoxifen & & & & \\
\hline
\end{tabular}

*Abbreviation: LC, local recurrence; M, metastasis; D, death; IBC, ipsilateral-breast cancer; CBC, contralateral breast cancer

95\% CrI $=1.14-1.92), \mathrm{RT}+$ anastrozole $(\mathrm{OR}=3.03,95 \%$ $\mathrm{CrI}=1.45-6.67)$ and $\mathrm{RT}+$ tamoxifen $(\mathrm{OR}=0.92,95 \% \mathrm{CrI}$ $=1.20-3.13)$.

\section{Ranking results}

According to the SUCRA presented in Table 3, the results between comparisons based on observational studies and RCTs and those based on RCTs alone were similar. RT + anastrozole ranked first in IBC, LC, M and $\mathrm{CBC}$, and $\mathrm{RT}+$ tamoxifen also exhibited good performance in terms of IBC, LC, and M. In addition, tamoxifen was associated with a lower risk of $\mathrm{CBC}$ compared to all treatments except for RT + anastrozole, and besides RT + anastrozole and RT + tamoxifen, RT alone also effectively reduced the events of LC and
IBC. However, no treatments exhibited outstanding performance with respect to D.

\section{DISCUSSION}

The number of diagnosed cases of DCIS has increased due to the advent of new mammography techniques, and this increase has resulted in the challenge of tailoring post-surgery adjuvant therapies to individual patients. Some DCIS patients with low-risk lesions have been over-treated, while others with high-risk lesions have been under-treated. This may be associated with the recurrence or development of invasive breast cancer (IBC) [64]. Accordingly, differentiating post-surgery adjuvant therapies based on their efficacy may provide clinicians with assistance in order to overcome these issues. 

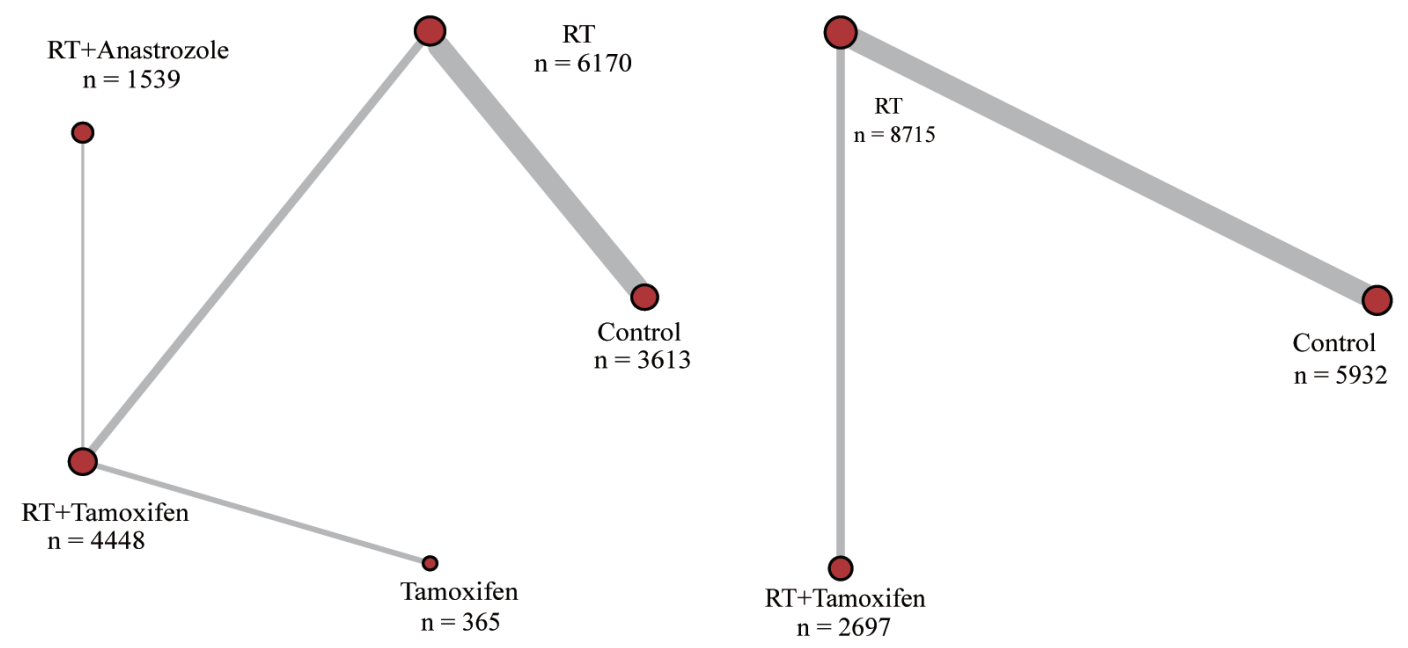

СBC

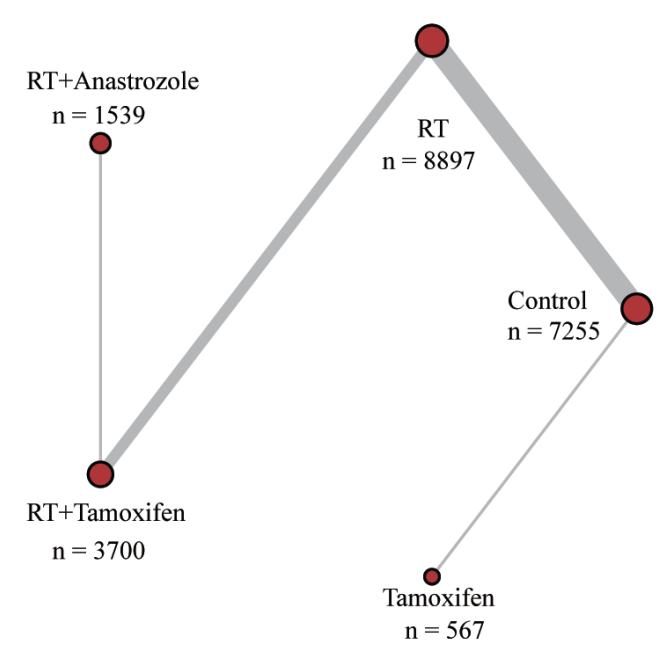

IBC

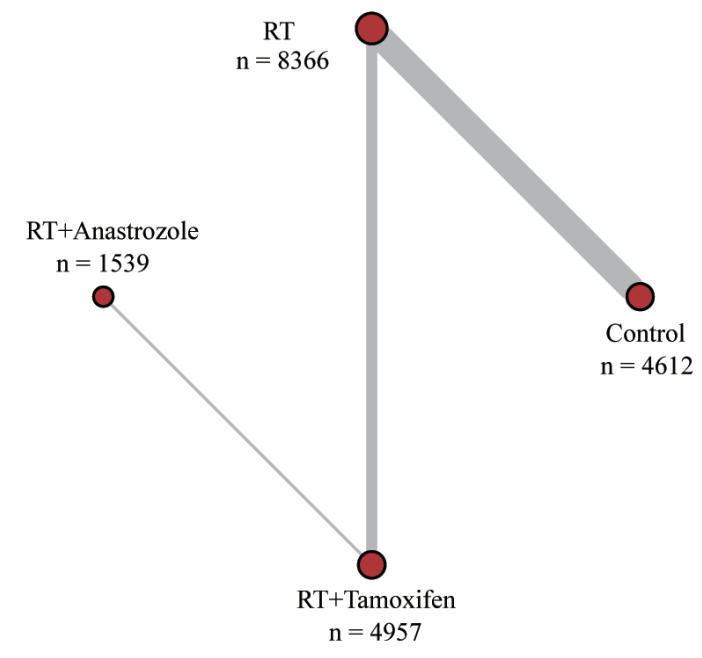

M

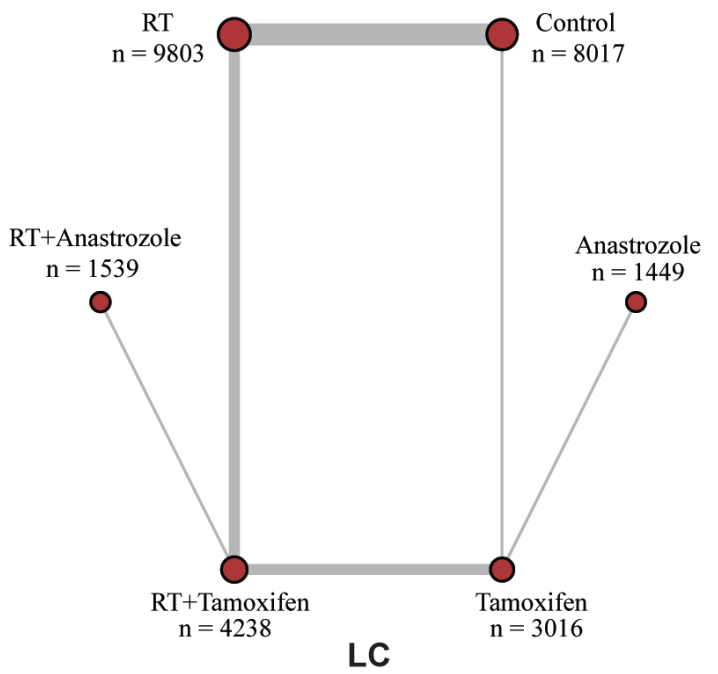

CBC: Contralateral breast cancer

D: Death

IBC: Ipsilateral-breast cancer

M: Metastasis

LC: Local recurrence

Figure 2: Network plot for each outcome: each node corresponds to an adjuvant therapy and direct comparisons are connected by solid lines. 
Table 3: Surface under the cumulative ranking curve (SUCRA)

\begin{tabular}{|l|c|c|c|c|c|}
\hline \multicolumn{7}{|c|}{ nRCT+RCT } \\
\hline & CBC & D & IBC & LC & M \\
\hline Anastrozole & - & - & - & 0.408 & - \\
\hline Control & 0.26 & 0.45 & 0.128 & 0.152 & 0.359 \\
\hline RT & 0.29 & 0.488 & 0.559 & 0.578 & 0.103 \\
\hline RT_Anastrozole & 0.705 & - & 0.758 & 0.816 & 0.874 \\
\hline RT_Tamoxifen & 0.561 & 0.561 & 0.736 & 0.754 & 0.664 \\
\hline Tamoxifen & 0.684 & - & 0.318 & 0.292 & - \\
\hline & \multicolumn{7}{|c|}{ RCT } & \multicolumn{3}{c|}{} \\
\hline & CBC & D & IBC & LC & M \\
\hline Anastrozole & - & - & - & 0.285 & - \\
\hline Control & 0.362 & 0.517 & 0.132 & 0.23 & 0.389 \\
\hline RT & 0.027 & 0.44 & 0.578 & 0.587 & 0.111 \\
\hline RT_Anastrozole & 0.92 & - & 0.755 & 0.89 & 0.866 \\
\hline RT_Tamoxifen & 0.584 & 0.543 & 0.739 & 0.823 & 0.634 \\
\hline Tamoxifen & 0.607 & - & 0.296 & 0.185 & - \\
\hline
\end{tabular}

This NMA evaluated five post-surgery treatments based on observational studies and RCTs. According to our results, treatments containing RT were effective

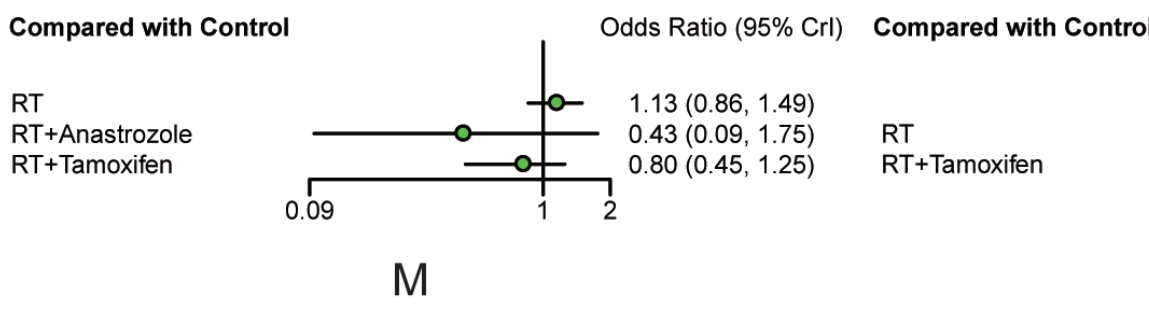

Compared with Control

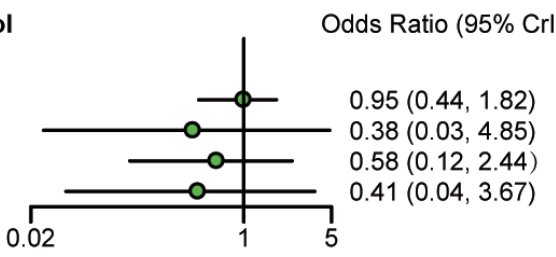

CBC

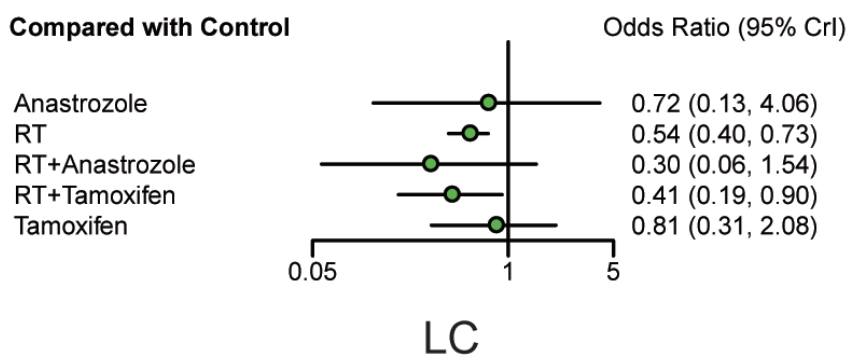

in reducing the rate of LC and IBC. Moreover, RT + anastrozole and RT + tamoxifen were also associated with lower risk of $\mathrm{M}$ and $\mathrm{CBC}$, which was confirmed by

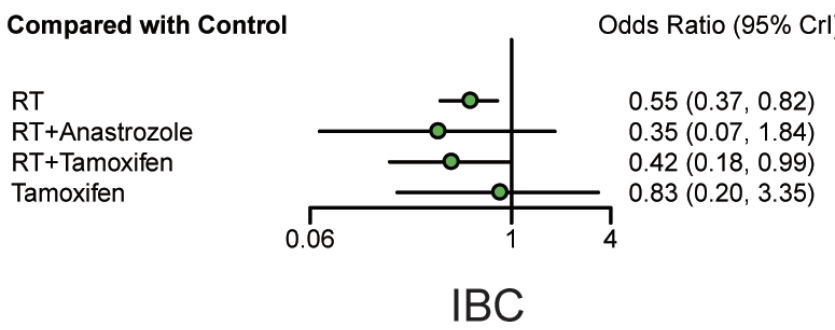

\section{CBC: Contralateral breast cancer \\ D: Death}

IBC: Ipsilateral-breast cancer

M: Metastasis

LC: Local recurrence

Figure 3: Forest plots of all outcomes based on observational studies and RCTs. ORs with corresponding 95\% CrIs were calculated to measure the relative efficacy of different treatments. 
previous studies. As suggested by a long-term follow-up study, which focused on four randomized trials comparing lumpectomy with or without RT, radiation significantly reduced the local failure rate in DCIS patients [65]. Besides, two phase III trials indicated that tamoxifen with a dose of $20 \mathrm{mg} /$ day reduced the risk of ipsilateral and contralateral events by approximately $30 \%[57,58]$.

However, due to the lack of evidence, this NMA did not cover an analysis of safety, and it was reported that about $11 \%-31 \%$ patients treated with RT + tamoxifen did not complete the five-year tamoxifen treatment [66]. This poor rate of compliance may have been the result of long-term toxic effects associated with endometrial cancer or vascular thrombotic events. It was also reported that both RT and tamoxifen may trigger severe adverse events such as endometrial cancers, venous thromboembolism and secondary malignancies [67-69]. Therefore, longterm follow-up studies that consider the efficacy of RT or tamoxifen should be carried out in order to provide a more comprehensive suggestion for clinical practice.

Moreover, according to this NMA, RT + anastrozole seemed to be slightly more effective than RT + tamoxifen. Actually, aromatase inhibitors are potentially more effective than tamoxifen for preventing recurrence in postmenopausal females with invasive breast cancer and positive ER [57]. Various aromatase inhibitors have offered effective alternatives to tamoxifen, but the
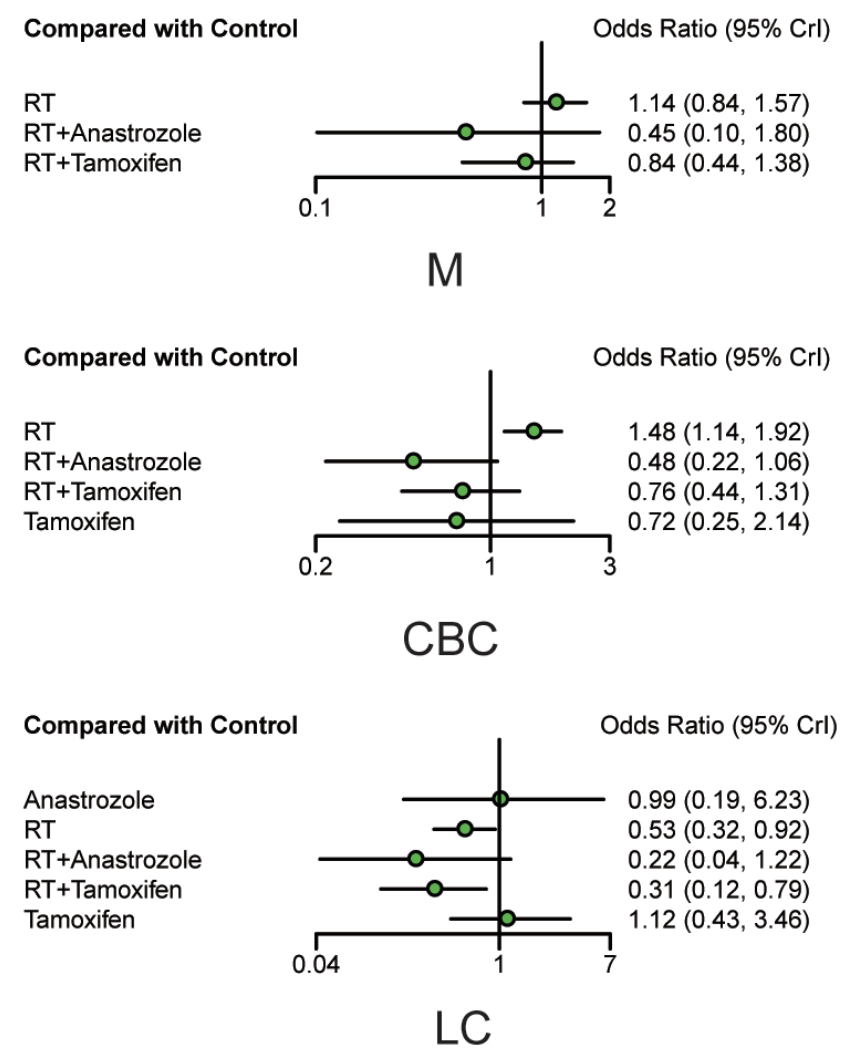

relative effectiveness of aromatase inhibitors compared to tamoxifen remains controversial. For instance, a randomized double-blinded trial (NSABP B-35) suggested that anastrozole significantly improved the breast cancerfree interval in DCIS patients under the age of 60 compared to the tamoxifen group, while another study reported no significant difference in the risk of overall recurrence between the anastrozole and tamoxifen group [70]. Therefore, although RT + anastrozole seemed to be more highly recommended than RT + tamoxifen, clinical decisions should be made based on several factors, including the patients' physical characteristics, age, excision method and tolerance level.

Our study provides guidance for discriminating between the available post-surgery adjuvant therapies, however our NMA does contain some inherent limitations. First of all, although a large number of studies were included, their differences in follow-up times may increase the heterogeneity of this study. For example, adverse events such as LC, metastasis, progression to invasive breast cancers or death are rare events; therefore, the likelihood of the occurrence of such events in each study may be proportional to the duration. Studies with longer follow-up durations may contain more of these events. Having acknowledged this, our study did not adjust for duration when adverse events were taken into account. Apart from that, other variables, including age,
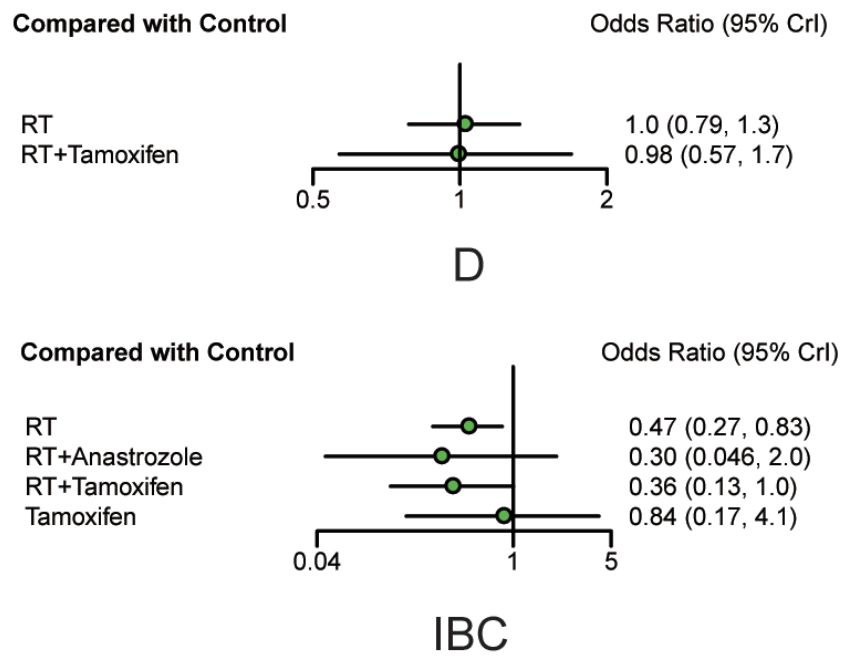

\author{
CBC: Contralateral breast cancer \\ D: Death \\ IBC: Ipsilateral-breast cancer \\ M: Metastasis
}

LC: Local recurrence

Figure 4: Forest plots of all outcomes based on RCTs. ORs with corresponding 95\% CrIs were calculated to measure the relative efficacy of different treatments. 
margin and hormone-receptor status, may also increase the heterogeneity of patients and thus weaken the reliability of the results. Therefore, more detailed analyses should be conducted before certain conclusions are drawn. Most of the included studies cover the comparison of RT and placebo (control group). However, few trials include the analysis of anastrozole. Also, due to a lack of evidence, outcome information under certain treatments, including anastrozole and tamoxifen, was missing, and more comprehensive studies should be carried out in the future.

Overall, our study is an excellent start, as it demonstrates that patients treated with post-surgery adjuvant therapies had significant reduction in the risk of LC and IBC. Of all the treatments, RT + tamoxifen and RT + anastrozole were the two most recommended therapies. However, due to the lack of evidence demonstrating their safety, they should be applied with extra care.

\section{MATERIALS AND METHODS}

\section{Systematic review and search for relevant studies}

This study is based on a systematic and thorough review, which was conducted at an early stage in order to ensure the quality of our network meta-analysis. The review team included an experienced statistician, a clinician with expert knowledge and reviewers with competent search and information retrieval skills. Our review team also examined the corresponding research question in order to ensure that our study could produce meaningful results. The following aspects were considered in the systematic literature review: study population, comparators of our interest, clinical outcome definitions, study inclusion criteria, data extraction procedures, study quality assessment and the selection of an appropriate data analysis approach.

We performed an extensive literature search based on our systematic review, using the following medical subject headings $(\mathrm{MeSH})$, in conjunction with their corresponding synonyms, to formulate a search strategy: DCIS of the breast, mastectomy (M), local excision (LE), $\mathrm{BCS}$, breast sector resection (BSR), wide local excision (WLE), lumpectomy (L), localized surgery (LS), postsurgery adjuvant endocrine therapy, post-surgery radiation therapy (RT), efficacy. We included both observational trials and RCTs in this NMA. We searched a variety of databases, including Embase, MEDLINE/PUBMED, Cochrane Library, and Science Citation Index (SCI), according to the criteria mentioned above. Two reviewers carried out the entire search process independently of one another, and any disagreements were subject to third-party discussion.

\section{Studies selection}

Retrieved articles were subject to the following eligibility criteria: 1) patients were at least 18 years old; 2) The diagnosis of DCIS must have been obtained by mammographic screening or histological examination; 3) Patients must have been treated by surgical procedures including mastectomy, M, L, LE, BCS, BSR, WLE, LS; 4) treatments must have contained at least two of the following treatments: tamoxifen, anastrozole, RT + tamoxifen, RT + anastrozole and placebo (control group); 5 ) outcomes must have included one of the following items, including LC, M, CBC, IBC and D; 6) Sufficient data for conducting a network meta-analysis could be obtained from studies. Studies which fell into one of the following categories were excluded: 1) duplicated studies; 2) meta-analysis or NMA; 3) reviews, abstracts, and case reports.

\section{Data extraction}

Raw data were extracted from eligible studies using a data extraction spreadsheet, including study characteristics, baseline demographics and raw/summary statistics of the corresponding outcomes. The baseline characteristics of all trials were collected, including first author, publication year, country, study design, subgroup, sample size, follow-up time, surgery type, treatment, group size and outcomes.

\section{Statistical analysis}

Software R 3.3.2 was used to conduct this Bayesian NMA and the random-effects assumption was adopted throughout our analysis due to the heterogeneous nature of included studies with respect to study design, population selection and following-up duration [71]. We used odds ratios (ORs) with 95\% credible intervals to measure the relative efficacy of each treatment under different outcomes. Furthermore, the SUCRA was computed to obtain the relative ranking of different treatments. Moreover, in order to guarantee the reliability of this NMA, RCTs were selected from all eligible studies and then analyzed following the steps above.

\section{Abbreviations}

ductal carcinoma in situ, DCIS; odds ratio, OR; surface under the cumulative ranking curve, SUCRA; radiotherapy, RT; local recurrence, LC; ipsilateral breast cancer, IBC. 


\section{ACKNOWLEDGMENTS}

This study was supported by the "Innovation Team Development Program of the Ministry of Education of China", the State Key Laboratory of Stem Cell and Regenerative Medicine of Yunnan Province and the Joint Research Program between the Science and Technology Bureau of Yunnan and Kunming Medical University.

\section{CONFLICTS OF INTEREST}

The authors declare no conflict of interest.

\section{REFERENCES}

1. Burstein HJ, Polyak K, Wong JS, Lester SC, Kaelin CM. Ductal carcinoma in situ of the breast. N Engl J Med. 2004; 350:1430-41.

2. Wong H, Lau S, Yau T, Cheung P, Epstein RJ. Presence of an in situ component is associated with reduced biological aggressiveness of size-matched invasive breast cancer. Br J Cancer. 2010; 102:1391-96.

3. Goodwin A, Parker S, Ghersi D, Wilcken N. Post-operative radiotherapy for ductal carcinoma in situ of the breast. Cochrane Database Syst Rev. 2013CD000563.

4. Petrelli F, Barni S. Tamoxifen added to radiotherapy and surgery for the treatment of ductal carcinoma in situ of the breast: a meta-analysis of 2 randomized trials. Radiother Oncol. 2011; 100:195-99.

5. Solin LJ, Fourquet A, Vicini FA, Haffty B, Taylor M, McCormick B, McNeese M, Pierce LJ, Landmann C, Olivotto IA, Borger J, de La Rochefordiere A, Schultz DJ. Salvage treatment for local recurrence after breastconserving surgery and radiation as initial treatment for mammographically detected ductal carcinoma in situ of the breast. Cancer. 2001; 91:1090-97.

6. Radford DM, Phillips NJ, Fair KL, Ritter JH, Holt M, Donis-Keller H. Allelic loss and the progression of breast cancer. Cancer Res. 1995; 55:5180-83.

7. Stratton MR, Collins N, Lakhani SR, Sloane JP. Loss of heterozygosity in ductal carcinoma in situ of the breast. J Pathol. 1995; 175:195-201.

8. Lavoué V, Fritel X, Antoine M, Beltjens F, Bendifallah $\mathrm{S}$, Boisserie-Lacroix $\mathrm{M}$, Boulanger L, Canlorbe $\mathrm{G}$, Catteau-Jonard S, Chabbert-Buffet N, Chamming's F, Chéreau E, Chopier J, et al, and Collège national des gynécologues obstétriciens français. Benign breast tumors: Recommendations of Collège National des Gynécologues Obstétriciens Français (CNGOF)-Short text. [Article in French] J Gynecol Obstet Biol Reprod (Paris). 2015; 44:1049-64. Benign breast tumors: Recommendations of College National des Gynecologues Obstetriciens Francais. CNGOF. -Short text

9. Petridis C, Brook MN, Shah V, Kohut K, Gorman P,
Caneppele M, Levi D, Papouli E, Orr N, Cox A, Cross SS, Dos-Santos-Silva I, Peto J, et al. Genetic predisposition to ductal carcinoma in situ of the breast. Breast Cancer Res. 2016; 18:22.

10. Nilsson C, Valachis A. The role of boost and hypofractionation as adjuvant radiotherapy in patients with DCIS: a meta-analysis of observational studies. Radiother Oncol. 2015; 114:50-55.

11. Wang SY, Shamliyan T, Virnig BA, Kane R. Tumor characteristics as predictors of local recurrence after treatment of ductal carcinoma in situ: a meta-analysis. Breast Cancer Res Treat. 2011; 127:1-14.

12. Sakorafas GH, Farley DR. Optimal management of ductal carcinoma in situ of the breast. Surg Oncol. 2003; 12:22140.

13. Fisher B, Land S, Mamounas E, Dignam J, Fisher ER, Wolmark N. Prevention of invasive breast cancer in women with ductal carcinoma in situ: an update of the National Surgical Adjuvant Breast and Bowel Project experience. Semin Oncol. 2001; 28:400-18.

14. Bijker N, Meijnen $\mathrm{P}$, Peterse JL, Bogaerts J, Van Hoorebeeck I, Julien JP, Gennaro M, Rouanet P, Avril A, Fentiman IS, Bartelink H, Rutgers EJ, Bartelink H, Rutgers EJ, and EORTC Breast Cancer Cooperative Group, and EORTC Radiotherapy Group. Breast-conserving treatment with or without radiotherapy in ductal carcinoma-in-situ: ten-year results of European Organisation for Research and Treatment of Cancer randomized phase III trial 10853 - a study by the EORTC Breast Cancer Cooperative Group and EORTC Radiotherapy Group. J Clin Oncol. 2006; 24:338187.

15. Fisher B, Dignam J, Wolmark N, Wickerham DL, Fisher ER, Mamounas E, Smith R, Begovic M, Dimitrov NV, Margolese RG, Kardinal CG, Kavanah MT, Fehrenbacher L, Oishi RH. Tamoxifen in treatment of intraductal breast cancer: National Surgical Adjuvant Breast and Bowel Project B-24 randomised controlled trial. Lancet. 1999; 353:1993-2000.

16. Nabholtz JM, Buzdar A, Pollak M, Harwin W, Burton G, Mangalik A, Steinberg M, Webster A, von Euler M, and Arimidex Study Group. Anastrozole is superior to tamoxifen as first-line therapy for advanced breast cancer in postmenopausal women: results of a North American multicenter randomized trial. J Clin Oncol. 2000; 18:375867.

17. Baum M, Budzar AU, Cuzick J, Forbes J, Houghton JH, Klijn JG, Sahmoud T, Group AT, and ATAC Trialists' Group. Anastrozole alone or in combination with tamoxifen versus tamoxifen alone for adjuvant treatment of postmenopausal women with early breast cancer: first results of the ATAC randomised trial. Lancet. 2002; 359:2131-39.

18. Lagios MD, Margolin FR, Westdahl PR, Rose MR. Mammographically detected duct carcinoma in situ. Frequency of local recurrence following tylectomy and 
prognostic effect of nuclear grade on local recurrence. Cancer. 1989; 63:618-24.

19. Baird RM, Worth A, Hislop G. Recurrence after lumpectomy for comedo-type intraductal carcinoma of the breast. Am J Surg. 1990; 159:479-81.

20. Cataliotti L, Distante V, Ciatto S, Bianchi S, Pacini P, Simoncini R, Rosselli Del Turco M, Cardona G, Falli F. Intraductal breast cancer: review of 183 consecutive cases. Eur J Cancer. 1992; 28A:917-20.

21. Fisher B, Costantino J, Redmond C, Fisher E, Margolese R, Dimitrov N, Wolmark N, Wickerham DL, Deutsch M, Ore L, Mamounas E, Poller W, Kavanah M. Lumpectomy compared with lumpectomy and radiation therapy for the treatment of intraductal breast cancer. N Engl J Med. 1993; 328:1581-86.

22. Kuske RR, Bean JM, Garcia DM, Perez CA, Andriole D, Philpott G, Fineberg B. Breast conservation therapy for intraductal carcinoma of the breast. Int J Radiat Oncol Biol Phys. 1993; 26:391-96.

23. Fisher ER, Costantino J, Fisher B, Palekar AS, Redmond C, Mamounas E, and The National Surgical Adjuvant Breast and Bowel Project Collaborating Investigators. Pathologic findings from the National Surgical Adjuvant Breast Project (NSABP) Protocol B-17. Intraductal carcinoma (ductal carcinoma in situ). Cancer. 1995; 75:1310-19.

24. Fentiman IS. Trials of treatment for non-invasive breast cancer. Recent Results Cancer Res. 1998; 152:135-42.

25. Habel LA, Daling JR, Newcomb PA, Self SG, Porter PL, Stanford JL, Seidel K, Weiss NS. Risk of recurrence after ductal carcinoma in situ of the breast. Cancer Epidemiol Biomarkers Prev. 1998; 7:689-96.

26. Boyages J, Delaney G, Taylor R. Predictors of local recurrence after treatment of ductal carcinoma in situ: a meta-analysis. Cancer. 1999; 85:616-28.

27. Fisher ER, Dignam J, Tan-Chiu E, Costantino J, Fisher B, Paik S, Wolmark N. Pathologic findings from the National Surgical Adjuvant Breast Project (NSABP) eight-year update of Protocol B-17: intraductal carcinoma. Cancer. 1999; 86:429-38.

28. Julien JP, Bijker N, Fentiman IS, Peterse JL, Delledonne V, Rouanet P, Avril A, Sylvester R, Mignolet F, Bartelink H, Van Dongen JA, and EORTC Breast Cancer Cooperative Group and EORTC Radiotherapy Group. Radiotherapy in breast-conserving treatment for ductal carcinoma in situ: first results of the EORTC randomised phase III trial 10853. Lancet. 2000; 355:528-33.

29. Kestin LL, Goldstein NS, Martinez AA, Rebner M, Balasubramaniam M, Frazier RC, Register JT, Pettinga J, Vicini FA. Mammographically detected ductal carcinoma in situ treated with conservative surgery with or without radiation therapy: patterns of failure and 10-year results. Ann Surg. 2000; 231:235-45.

30. Ringberg A, Idvall I, Fernö M, Anderson H, Anagnostaki L, Boiesen P, Bondesson L, Holm E, Johansson S, Lindholm
$\mathrm{K}$, Ljungberg O, Ostberg G. Ipsilateral local recurrence in relation to therapy and morphological characteristics in patients with ductal carcinoma in situ of the breast. Eur $\mathrm{J}$ Surg Oncol. 2000; 26:444-51.

31. Silverstein MJ. Ductal carcinoma in situ of the breast. Annu Rev Med. 2000; 51:17-32.

32. Weng EY, Juillard GJ, Parker RG, Chang HR, Gornbein JA. Outcomes and factors impacting local recurrence of ductal carcinoma in situ. Cancer. 2000; 88:1643-49.

33. Bijker N, Peterse JL, Duchateau L, Julien JP, Fentiman IS, Duval C, Di Palma S, Simony-Lafontaine J, de Mascarel I, van de Vijver MJ. Risk factors for recurrence and metastasis after breast-conserving therapy for ductal carcinoma-insitu: analysis of European Organization for Research and Treatment of Cancer Trial 10853. J Clin Oncol. 2001; 19:2263-71.

34. Chan KC, Knox WF, Sinha G, Gandhi A, Barr L, Baildam AD, Bundred NJ. Extent of excision margin width required in breast conserving surgery for ductal carcinoma in situ. Cancer. 2001; 91:9-16.

35. Cutuli B, Cohen-Solal-Le Nir C, De Lafontan B, Mignotte H, Fichet V, Fay R, Servent V, Giard S, Charra-Brunaud C, Auvray H, Penault-Llorca F, Charpentier JC. Ductal carcinoma in situ of the breast results of conservative and radical treatments in 716 patients. Eur J Cancer. 2001; 37:2365-72.

36. Fisher ER, Anderson S, Tan-Chiu E, Fisher B, Eaton L, Wolmark N. Fifteen-year prognostic discriminants for invasive breast carcinoma: National Surgical Adjuvant Breast and Bowel Project Protocol-06. Cancer. 2001 (Suppl); 91:1679-87.

37. Jha MK, Avlonitis VS, Griffith CD, Lennard TW, Wilson RG, McLean LM, Dawes PD, Shrimankar J. Aggressive local treatment for screen-detected DCIS results in very low rates of recurrence. Eur J Surg Oncol. 2001; 27:454-58.

38. Miller NA, Chapman JA, Fish EB, Link MA, Fishell E, Wright B, Lickley HL, McCready DR, Hanna WM. In situ duct carcinoma of the breast: clinical and histopathologic factors and association with recurrent carcinoma. Breast J. 2001; 7:292-302.

39. Cutuli B, Cohen-Solal-le Nir C, de Lafontan B, Mignotte H, Fichet V, Fay R, Servent V, Giard S, Charra-Brunaud C, Lemanski C, Auvray H, Jacquot S, Charpentier JC. Breastconserving therapy for ductal carcinoma in situ of the breast: the French Cancer Centers' experience. Int J Radiat Oncol Biol Phys. 2002; 53:868-79.

40. Houghton J, George WD, Cuzick J, Duggan C, Fentiman IS, Spittle M, and UK Coordinating Committee on Cancer Research, and Ductal Carcinoma in situ Working Party, and DCIS trialists in the UK, Australia, and New Zealand. Radiotherapy and tamoxifen in women with completely excised ductal carcinoma in situ of the breast in the UK, Australia, and New Zealand: randomised controlled trial. Lancet. 2003; 362:95-102. 
41. Lara JF, Young SM, Velilla RE, Santoro EJ, Templeton SF. The relevance of occult axillary micrometastasis in ductal carcinoma in situ: a clinicopathologic study with long-term follow-up. Cancer. 2003; 98:2105-13.

42. Warren JL, Weaver DL, Bocklage T, Key CR, Platz CE, Cronin KA, Ballard-Barbash R, Willey SC, Harlan LC. The frequency of ipsilateral second tumors after breastconserving surgery for DCIS: a population based analysis. Cancer. 2005; 104:1840-48.

43. Bijker N, Meijnen $\mathrm{P}$, Peterse JL, Bogaerts J, Van Hoorebeeck I, Julien JP, Gennaro M, Rouanet P, Avril A, Fentiman IS, Bartelink H, Rutgers EJ, and EORTC Breast Cancer Cooperative Group, and EORTC Radiotherapy Group. Breast-conserving treatment with or without radiotherapy in ductal carcinoma-in-situ: ten-year results of European Organisation for Research and Treatment of Cancer randomized phase III trial 10853 - a study by the EORTC Breast Cancer Cooperative Group and EORTC Radiotherapy Group. J Clin Oncol. 2006; 24:3381-87.

44. Emdin SO, Granstrand B, Ringberg A, Sandelin K, Arnesson LG, Nordgren H, Anderson H, Garmo H, Holmberg L, Wallgren A, and Swedish Breast Cancer Group. SweDCIS: radiotherapy after sector resection for ductal carcinoma in situ of the breast. Results of a randomised trial in a population offered mammography screening. Acta Oncol. 2006; 45:536-43.

45. Omlin A, Amichetti M, Azria D, Cole BF, Fourneret P, Poortmans P, Naehrig D, Miller RC, Krengli M, Gutierrez Miguelez C, Morgan D, Goldberg H, Scandolaro L, et al. Boost radiotherapy in young women with ductal carcinoma in situ: a multicentre, retrospective study of the Rare Cancer Network. Lancet Oncol. 2006; 7:652-56.

46. Smith BD, Haffty BG, Buchholz TA, Smith GL, Galusha DH, Bekelman JE, Gross CP. Effectiveness of radiation therapy in older women with ductal carcinoma in situ. J Natl Cancer Inst. 2006; 98:1302-10.

47. Ben-David MA, Sturtz DE, Griffith KA, Douglas KR, Hayman JA, Lichter AS, Pierce LJ. Long-term results of conservative surgery and radiotherapy for ductal carcinoma in situ using lung density correction: the University of Michigan experience. Breast J. 2007; 13:392-400.

48. Fisher ER, Land SR, Saad RS, Fisher B, Wickerham DL, Wang M, Costantino JP, Wolmark N. Pathologic variables predictive of breast events in patients with ductal carcinoma in situ. Am J Clin Pathol. 2007; 128:86-91.

49. Rakovitch E, Pignol JP, Hanna W, Narod S, Spayne J, Nofech-Mozes S, Chartier C, Paszat L. Significance of multifocality in ductal carcinoma in situ: outcomes of women treated with breast-conserving therapy. J Clin Oncol. 2007; 25:5591-96.

50. Schouten van der Velden AP, van Vugt R, Van Dijck JA, Leer JW, Wobbes T. Local recurrences after different treatment strategies for ductal carcinoma in situ of the breast: a population-based study in the East Netherlands. Int J Radiat Oncol Biol Phys. 2007; 69:703-10.
51. Chuwa EW, Tan VH, Tan PH, Yong WS, Ho GH, Wong CY. Treatment for ductal carcinoma in situ in an Asian population: outcome and prognostic factors. ANZ J Surg. $2008 ; 78: 42-48$.

52. Di Saverio S, Catena F, Santini D, Ansaloni L, Fogacci T, Mignani S, Leone A, Gazzotti F, Gagliardi S, De Cataldis A, Taffurelli M. 259 Patients with DCIS of the breast applying USC/Van Nuys prognostic index: a retrospective review with long term follow up. Breast Cancer Res Treat. 2008; 109:405-16.

53. Holmberg L, Garmo H, Granstrand B, Ringberg A, Arnesson LG, Sandelin K, Karlsson P, Anderson H, Emdin S. Absolute risk reductions for local recurrence after postoperative radiotherapy after sector resection for ductal carcinoma in situ of the breast. J Clin Oncol. 2008; 26:1247-52.

54. Meijnen P, Oldenburg HS, Peterse JL, Bartelink H, Rutgers EJ. Clinical outcome after selective treatment of patients diagnosed with ductal carcinoma in situ of the breast. Ann Surg Oncol. 2008; 15:235-43.

55. Rudloff U, Jacks LM, Goldberg JI, Wynveen CA, Brogi E, Patil S, Van Zee KJ. Nomogram for predicting the risk of local recurrence after breast-conserving surgery for ductal carcinoma in situ. J Clin Oncol. 2010; 28:3762-69.

56. Tunon-de-Lara C, Lemanski C, Cohen-Solal-Le-Nir C, de Lafontan B, Charra-Brunaud C, Gonzague-Casabianca L, Mignotte H, Fondrinier E, Giard S, Quetin P, Auvray H, Cutuli B. Ductal carcinoma in situ of the breast in younger women: a subgroup of patients at high risk. Eur J Surg Oncol. 2010; 36:1165-71.

57. Cuzick J, Sestak I, Pinder SE, Ellis IO, Forsyth S, Bundred NJ, Forbes JF, Bishop H, Fentiman IS, George WD. Effect of tamoxifen and radiotherapy in women with locally excised ductal carcinoma in situ: long-term results from the UK/ANZ DCIS trial. Lancet Oncol. 2011; 12:21-29.

58. Wapnir IL, Dignam JJ, Fisher B, Mamounas EP, Anderson SJ, Julian TB, Land SR, Margolese RG, Swain SM, Costantino JP, Wolmark N. Long-term outcomes of invasive ipsilateral breast tumor recurrences after lumpectomy in NSABP B-17 and B-24 randomized clinical trials for DCIS. J Natl Cancer Inst. 2011; 103:478-88.

59. Donker M, Litière S, Werutsky G, Julien JP, Fentiman IS, Agresti R, Rouanet P, de Lara CT, Bartelink H, Duez N, Rutgers EJ, Bijker N. Breast-conserving treatment with or without radiotherapy in ductal carcinoma In Situ: 15-year recurrence rates and outcome after a recurrence, from the EORTC 10853 randomized phase III trial. J Clin Oncol. 2013; 31:4054-59.

60. Wärnberg F, Garmo H, Emdin S, Hedberg V, Adwall L, Sandelin K, Ringberg A, Karlsson P, Arnesson LG, Anderson H, Jirström K, Holmberg L. Effect of radiotherapy after breast-conserving surgery for ductal carcinoma in situ: 20 years follow-up in the randomized SweDCIS Trial. J Clin Oncol. 2014; 32:3613-18.

61. McCormick B, Winter K, Hudis C, Kuerer HM, Rakovitch 
E, Smith BL, Sneige N, Moughan J, Shah A, Germain I, Hartford AC, Rashtian A, Walker EM, et al. RTOG 9804: a prospective randomized trial for good-risk ductal carcinoma in situ comparing radiotherapy with observation. J Clin Oncol. 2015; 33:709-15.

62. Forbes JF, Sestak I, Howell A, Bonanni B, Bundred N, Levy C, von Minckwitz G, Eiermann W, Neven P, Stierer M, Holcombe C, Coleman RE, Jones L, et al, and IBIS-II investigators. Anastrozole versus tamoxifen for the prevention of locoregional and contralateral breast cancer in postmenopausal women with locally excised ductal carcinoma in situ (IBIS-II DCIS): a double-blind, randomised controlled trial. Lancet. 2016; 387:866-73.

63. Margolese RG, Cecchini RS, Julian TB, Ganz PA, Costantino JP, Vallow LA, Albain KS, Whitworth PW, Cianfrocca ME, Brufsky AM, Gross HM, Soori GS, Hopkins JO, et al. Anastrozole versus tamoxifen in postmenopausal women with ductal carcinoma in situ undergoing lumpectomy plus radiotherapy (NSABP B-35): a randomised, double-blind, phase 3 clinical trial. Lancet. 2016; 387:849-56.

64. Mitchell KB, Kuerer H. Ductal Carcinoma In Situ: Treatment Update and Current Trends. Curr Oncol Rep. 2015; 17:48.

65. Lebeau A, Kühn T. Updates in the treatment of ductal carcinoma in situ of the breast. Curr Opin Obstet Gynecol. 2016; 28:49-58.
66. Johnston SR. Endocrine treatment for ductal carcinoma in situ: balancing risks and benefits. Lancet. 2016; 387:81921.

67. Tamoxifen for early breast cancer: an overview of the randomised trials. Early Breast Cancer Trialists' Collaborative Group. Lancet. 1998; 351:1451-67.

68. Fisher B, Costantino JP, Wickerham DL, Redmond CK, Kavanah M, Cronin WM, Vogel V, Robidoux A, Dimitrov N, Atkins J, Daly M, Wieand S, Tan-Chiu E, et al. Tamoxifen for prevention of breast cancer: report of the National Surgical Adjuvant Breast and Bowel Project P-1 Study. J Natl Cancer Inst. 1998; 90:1371-88.

69. Grantzau T, Overgaard J. Risk of second non-breast cancer after radiotherapy for breast cancer: a systematic review and meta-analysis of 762,468 patients. Radiother Oncol. 2015; 114:56-65.

70. Forbes JF, Sestak I, Howell A, Bonanni B, Bundred N, Levy C, von Minckwitz G, Eiermann W, Neven P, Stierer M, Holcombe C, Coleman RE, Jones L, et al, and IBIS-II investigators. Anastrozole versus tamoxifen for the prevention of locoregional and contralateral breast cancer in postmenopausal women with locally excised ductal carcinoma in situ (IBIS-II DCIS): a double-blind, randomised controlled trial. Lancet. 2016; 387:866-73.

71. Panagiotou OA. Network Meta-Analysis: Evidence Synthesis With Mixed Treatment Comparison. Am J Epidemiol. 2015kwu471. 